\title{
RANCANG BANGUN ALAT TES KEBOCORAN AIR CYLINDER HEAD PADA MESIN ANGLO BELGIAN CORP TYPE 12VDCZ PT PLN (PERSERO) SEKTOR PEMBANGKITAN MALUKU PLTD POKA
}

\author{
J. M. Tupan \\ Program Studi Teknik Industri, Fakultas Teknik Universitas Pattimura, Ambon \\ W. M. E. Wattimena \\ Program Studi Teknik Mesin, Fakultas Teknik Universitas Pattimura, Ambon \\ Hastony I Pranata \\ PLN Wilayah Maluku dan Maluku Utara
}

\begin{abstract}
ABSTRAK
Salah satu mesin yang digunakan pada PLTD Poka adalah mesin dengan merk Anglo Belgian Corps $(A B C)$. Apabila terjadi pada saat awal pengecekan sebelum dilakukan start ditemukan level oli yang meningkat dari batas normal dan ditemukan air pada stick penunjuk level. Setelah di lakukan blow up ternyata keluar air dari salah satu cylinder head, kemudian komponen Cylinder Head dilepas untuk di lakukan pengecekan namun tidak adanya alat untuk mengetes kebocoran sehingga pengecekan hanya dilakukan secara visual dan cylinder head yang bocor diganti dengan cylinder head yang baru untuk dipasang kembali agar mesin dapat beroperasi. Dengan adanya permasalahan perlu adanya sebuah alat yang dapat mengetahui kebocoran air pada cylinder head sehingga effisiensi waktu pemelihaaan lebih cepat dan biaya pemeliharaan lebih hemat. Penelitian ini bertujuan untuk merancang $n$ membuat sebuah alat agar kebocoran dalam saluran air pendingin cylinder head agar kerugian-kerugian karena kebocoran air pendingin dapat di hindari. Dengan diskusi dengan pegawai PLTD di dapatkan desain akhir yang sesuai dengan desain cylinder head mesin Anglo Belgian Corp. 12 VDCZ dan dengan biaya pembuatan sebesar Rp. 1.762.000 dapat menghemat biaya menghemat biaya akibat tidak masuknya mesin pada sistem sebesar Rp. 8.116.400 dan dapat menghemat penggunaan oli sebesar Rp. 28.238.000. karena manfaat yang sangat besar pada PLN maka hendaknya PLN dapat mengimplemtasikan kepada seluruh unit yang memiliki mesin Anglo Belgian Corp. Type 12VDZ.
\end{abstract}

Kata kunci : Kebocoran Cylinder Head, ABC 12VDCZ, Rancang Bangun

\section{ABSTRACT}

One of the machines is operated in the PLTD Poka is Anglo Belgian Corps (ABC). When an initial checkt is started, it is found that the oil level rises from the normal limit and water is found on the level stick indicator. After the blow up done, water comes out of one of the cylinder heads, then the Cylinder Head component is removed for checking. The checking process is done manually and visually because there is no leakage checking tools. An unavailability of the tools is the reason to design the cylinder head water leakage tools. Therefore, this research aims to design the tools that prevent the leakage of head cooling water channel. By discussions with PLTD employees, a final design that was suitable with the Anglo Belgian Corp engine cylinder head design was designed. The manufacturing cost is Rp. 1,762,000 so it can decrease cost for entering system Rp. 8,116,400 and can save oil usage of Rp. 28,238,000.

Keywords: Cylinder Head Leaks, ABC 12VDCZ, Design and Build

\section{PENDAHULUAN}

Dewasa ini perkembangan ilmu pengetahuan dan teknologi telah mengalami banyak sekali perkembangan dalam berbagai bidang, untuk itu dibutuhkan tenaga-tenaga ahli dibidangnya. Namun disisi lain hal itu juga merupakan sebuah tantangan bagi kita semua untuk selalu meningkatkan kemampuan sumber daya manusia, agar mampu menjadi sumber daya yang handal dan mampu bersaing untuk menghadapi segala tantangan yang ada pada dewasa ini.

Energi listrik sangat dibutuhkan bagi masyarakat modern sekarang ini. Peningkatan kebutuhan energi listrik tidak saja dipengaruhi oleh banyaknya penduduk di suatu wilayah tetapi juga faktor aktivitas ekonomi penduduk yang terus meningkat untuk memenuhi kebutuhan hidupnya. Semakin tinggi aktivitas ekonomi maka semakin besar kebutuhan energi listriknya. Dapat dipastikan bahwa pertumbuhan suatu masyarakat modern, kebutuhan energi listrik pada umumnya akan meningkat sebanding dengan tingkat aktivitas ekonomi dan juga jumlah penduduk dalam wilayah tersebut. 
Ketersediaan energi listrik yang memadai akan mendorong pembangunan daerah misalnya petumbuhan pada sektor industri, bisnis, pelayanan publik. Disamping itu, kualitas hidup masyarakat juga meningkat seiring dengan semakin banyaknya masyarakat yang mengakses energi listrik untuk memenuhi kebutuhan sehari-hari. Dengan demikian, dapat dipastikan bahwa energi listrik sangat dibutuhkan dalam kegiatan sehari-hari, sehingga dibutuhkan suplai energi listrik yang maksimal dengan memperhatikan sinergi antara sumber daya alam yang tersedia dan kemampuan sumber daya manusia yang mengelolanya.

Salah satu pembangkit listrik yang dapat menghasilkan energi listrik adalah Pembangkit Listrik Tenaga Diesel (PLTD). PLTD ialah Pembangkit listrik yang menggunakan mesin diesel yang berbahan bakar High Speed Diesel Oil (HSDO) sebagai penggerak mula (prime mover). Prime mover merupakan peralatan yang mempunyai fungsi menghasilkan energi mekanis yang diperlukan untuk memutar rotor generator. Kegunaan utama PLTD adalah penyedia energi listrik yang dapat berfungsi untuk pusat pembangkit, sebagai cadangan (Stand by Plant), beban puncak, cadangan untuk keadaan darurat (emergency).

PLTD Poka merupakan unit pembangkitan yang berada di Kota Ambon, Provinsi Maluku. PLTD Poka merupakan pembangkit yang menggunakan mesin diesel untuk menyuplai kebutuhan listrik di Kota Ambon. Tentunya pengoperasian mesin yang baik dan handal dibutuhkan untuk dapat menyuplai kebutuhan beban. Saat ini, PLTD Poka memiliki 7 Satuan Pembangkit Diesel yang terdiri atas 3 Unit Mesin GMT, 2 Unit Mesin Cattepilar dan 2 Unit Mesin ABC.

Salah satu mesin yang digunakan pada PLTD Poka adalah mesin dengan merk Anglo Belgian Corps (ABC). Apabila terjadi pada saat awal pengecekan sebelum dilakukan start ditemukan level oli yang meningkat dari batas normal dan ditemukan air pada stick penunjuk level. Setelah di lakukan blow up ternyata keluar air dari salah satu Cylinder Head, kemudian komponen Cylinder Head dilepas untuk di lakukan pengecekan namun tidak adanya alat untuk mengetes kebocoran sehingga pengecekan hanya dilakukan secara visual dan Cylinder Head yang bocor diganti dengan Cylinder Head yang baru untuk dipasang kembali agar mesin dapat beroperasi dan serta kebocoran pada cylinder head tidak dilaksanakan blow up saat start maka cylinder head dapat terlempar dari posisinya dan membahayakan operator yang sedang jaga di sana. Dengan adanya permasalahan tesebut penulis mencoba merancang sebuah alat yang dapat mengetahui kebocoran air pada Cylinder Head saat di lepas dari mesin sehingga effisiensi waktu pemelihaaan lebih cepat dan biaya pemeliharaan lebih hemat.

Tujuan dari penulisan ini adalah untuk mengetahui kebocoran pada Cylinder Head saat Cylinder Head dilepas dari mesin Anglo Belgian Corp PLTD Poka.

\section{LANDASAN TEORI}

\section{Mesin Anglo Belgian Corp ( ABC) 12 VDCZ}

Anglo Belgian Corporation (ABC) adalah produsen mesin diesel kecepatan menengah dari Belgia, terutama untuk pasar laut, serta mesin stasioner dan lokomotif. Pada tanggal 26 Oktober 1912 perusahaan Anglo Belgia didirikan. Perusahaan tersebut memproduksi mesin semi diesel baru. Salah satu investornya adalah perusahaan Onghena yang merupakan produsen mesin gas dan akan menyumbangkan bagian dari ruang pabrik dan mesin mereka untuk memproduksi mesin baru tersebut. 8 (delapan) investor termasuk Onghena masing-masing menyumbang 500.000 franc Belgia terhadap perusahaan tersebut; investor kesembilan perusahaan Carels Brothers menyumbang lisensi manufaktur mesin diesel sebagai imbalan atas pengembalian 5\% dari perputaran perusahaan. Mesin DZC yang dimodifikasi berhasil, seperti hubungannya dengan Ogepar. Meskipun runtuhnya industri perkapalan Belgia, pasar baru ditemukan termasuk pembangkit listrik luar negeri. Pada tahun 1997 desain mesin DZC dalam formasi V dimulai, dan rentang daya dari seri DZC diperluas menjadi $5.000 \mathrm{hp}(3.700 \mathrm{~kW})$.

Berikut ini adalah spesifikasi teknis Anglo Belgian Corp ( ABC) 12 VDCZ :

- $\quad$ Continous power ISO3046/1

$\mathrm{Ne}=\mathrm{kW} / \mathrm{V} 12-\mathrm{kW} / \mathrm{V} 16$

- $\quad$ Angka revolusi/menit

$\mathrm{n}=\mathrm{rev} / \mathrm{min}$

- Tekanan efektif rata-rata

- $\quad$ Tekanan pembakaran maksimal

- Kecepatan piston rata-rata pada nominal kecepatan mesin

$$
\begin{array}{ll}
\mathrm{Pe} & =\mathrm{bar} \\
\mathrm{Pmax} & =\mathrm{bar} \\
\mathrm{Cm} & =\mathrm{m} / \mathrm{s}
\end{array}
$$


Dimensi Mesin Anglo Belgian Corporation (ABC)

\begin{tabular}{|c|c|}
\hline Nomor Silinder & 12 or 16 in $\mathrm{V}$ \\
\hline Swept volume per Silinder & $15,95 \mathrm{dm}^{3}$ \\
\hline Compression Ratio & $12,1 / 1$ \\
\hline Total swept volume & $\begin{array}{l}191,4 \mathrm{dm}^{3} / \mathrm{V} 12 \\
255,2 \mathrm{dm}^{3} / \mathrm{V} 16\end{array}$ \\
\hline Bore & $256 \mathrm{~mm}$ \\
\hline Stroke & $310 \mathrm{~mm}$ \\
\hline Diameter main bearing shell & $240 \mathrm{~mm}$ \\
\hline Diameter penghubung rod bearing shell & $210 \mathrm{~mm}$ \\
\hline Diameter pin piston & $110 \mathrm{~mm}$ \\
\hline Diameter camshaft bearing & $82 \mathrm{~mm}$ \\
\hline Diameter plunger pompa injeksi & $20 \mathrm{~mm}$ \\
\hline Benang cylinder head stud & M24 x 2 \\
\hline Panjang penghubung rod & $620 \mathrm{~mm}$ \\
\hline Lebar main bearing & $78 \mathrm{~mm}$ \\
\hline Lebar penghubung rod bearing & $72 \mathrm{~mm}$ \\
\hline Lebar penghubung rod bush & $65 \mathrm{~mm}$ \\
\hline Panjang tappets & $738 \mathrm{~mm}$ \\
\hline Panjang cylinder block studs & $376 \mathrm{~mm}$ \\
\hline Tinggi chrome-plated fire ring & $5 \mathrm{~mm}$ \\
\hline Tinggi compression spring & $4 \mathrm{~mm}$ \\
\hline Tinggi oil scraper ring & $8 \mathrm{~mm}$ \\
\hline Angkat katup masuk & $20,40 \mathrm{~mm}$ \\
\hline Angkat katup keluar & $20,40 \mathrm{~mm}$ \\
\hline Angkat nozzle needle & $0,6 \mathrm{~mm}$ \\
\hline Angkat inlet cam & $18,3 \mathrm{~mm}$ \\
\hline Angkat injection cam & $18 \mathrm{~mm}$ \\
\hline Jarak antar silinder & $380 \mathrm{~mm}$ \\
\hline Angka per katup masuk silinder & 2 \\
\hline Angka per katup keluar silinder & 2 \\
\hline Angka per cylinder top piston ring & 1 \\
\hline Angka per cylinder compression spring & 2 \\
\hline Angka per cylinder oil scraper spring & 1 \\
\hline
\end{tabular}


Tekanan Seluruh Sistem Mesin Anglo Belgian Corporation (ABC)

\begin{tabular}{|c|c|c|c|}
\hline & $\begin{array}{l}\text { Tekanan } \\
\text { Pembuka } \\
\quad \text { (bar) }\end{array}$ & $\begin{array}{l}\text { Tekanan } \\
\text { Pekerjaan } \\
\text { (bar) }\end{array}$ & $\begin{array}{c}\text { Bukti } \\
\text { Tekanan } \\
\text { (bar) }\end{array}$ \\
\hline $\begin{array}{l}\text { Cylinder head: } \\
\text { - Ruang pembakaran } \\
\text { - Ruang pendingin air }\end{array}$ & - & $\begin{array}{c}\text { Max. } 125 \\
3\end{array}$ & $\begin{array}{c}150 \\
5\end{array}$ \\
\hline $\begin{array}{l}\text { Cylinder block: } \\
\text { - Ruang pendingin air }\end{array}$ & - & 3 & 5 \\
\hline $\begin{array}{l}\text { Pendingin udara: } \\
\text { - Ruang air } \\
\text { - Ruang udara }\end{array}$ & - & $\begin{array}{l}3 \\
2\end{array}$ & $\begin{array}{l}6 \\
3\end{array}$ \\
\hline $\begin{array}{l}\text { Fresh Water Cooler: } \\
\text { - Sea water side } \\
\text { - Fresh water side }\end{array}$ & - & $\begin{array}{l}3 \\
5\end{array}$ & $\begin{array}{l}7,5 \\
7,5\end{array}$ \\
\hline $\begin{array}{l}\text { Pompa injeksi bahan bakar } \\
\text { - Plunger and liner } \\
\text { - Body }\end{array}$ & - & $\begin{array}{c}\text { Max. } 1200 \\
-\end{array}$ & $\overline{7}$ \\
\hline Suplai bahan bakar & - & Gasoil max 2,5 & - \\
\hline Pipa injeksi & - & Max. 1200 & - \\
\hline Opening injection needle & 275 & - & - \\
\hline $\begin{array}{l}\text { Katup pengaman } \\
\text { (cylinder head) }\end{array}$ & $150 \pm 2$ & - & - \\
\hline $\begin{array}{l}\text { Katup pengaman } \\
\text { (crankcase) }\end{array}$ & 0,05 & - & - \\
\hline $\begin{array}{l}\text { Tekanan oli pelumas } \\
\text { (entrance motor) } \\
\text { - } 720 \text { dan } 750 \mathrm{rev} / \mathrm{min} \\
\text { - } 900 \mathrm{dan} 1.000 \mathrm{rev} / \mathrm{min}\end{array}$ & - & $\begin{array}{l}4,85 \\
5,00 \\
\end{array}$ & $\begin{array}{l}- \\
-\end{array}$ \\
\hline $\begin{array}{l}\text { Idling speed } \\
-300 \mathrm{rev} / \mathrm{min} \\
-380 \mathrm{rev} / \mathrm{min} \\
\end{array}$ & - & $\begin{array}{l}2 \text { a } 2,5 \\
2,5 \text { a } 3\end{array}$ & - \\
\hline
\end{tabular}

\section{Sistem Pendingin Anglo Belgian 12 VDCZ}

Eksekusi ini mencakup HT-Circuit tertutup dan LT-Circuit tertutup yang diisi dengan air treatment pada radiator dengan double circuit.

1. $\quad$ Sistem HT-cooling

HT-softwaterpump (4) memompa air ke dalam mesin melalui water inlet manifold (5). Di dalam mesin, air mengalir dari inlet manifold (5) di atas liner ke cylinderhead dan dikumpulkan di water outlet manifold. HT-circuit ini juga mencakup pendinginan turbo-charger (exhaust gas side) yang terhubung pada satu sisi water inlet manifold dan sisi lainnya ke water outlet manifold. Dari outlet manifold (6), air pendingin melewati aliran yang mengatur diafragma (7) ke regulator termostatik (8). Dari situ, alirannya terbelah. Sebagian dari air pendingin langsung kembali ke sisi isap HT-waterpump; dan bagian lainnya aliran air diarahkan ke radiator (9). Dari radiator, air kembali ke sisi isap pompa (14).

HT-circuit ini juga mencakup sambungan untuk pengaturan panas: katup pintu air (11) dan katup penutup (12).

2. $\quad$ Sistem LT-cooling

LT-circuit juga merupakan sistem tertutup. LT-waterpump (1) membawa air ke charge air cooler (2) dan selanjutnya ke lub-oil cooler (3) serta ke LT-side radiator (9). Baik rangkaian HT dan LT berisi expansion vessel (14) dengan katup pelampung (float switches).

3. Pengawasan selama operasi

A. HT-circuit

Pengawasan mengacu pada:

a) Suhu air pendingin.

Suhu air pendingin dikendalikan secara termostatik. Suhu bekerja normal pada rentang antara 80 dan 85 derajat celcius pada engine outlet. Pengawasan suhu dapat dilakukan secara otomatis oleh 
perangkat peringatan dini yang diatur oleh alarm mulai pada suhu 90 derajat celcius dan pada suhu 95 derajat celcius. Jika suhu air pendingin naik, penyebabnya harus ditentukan.

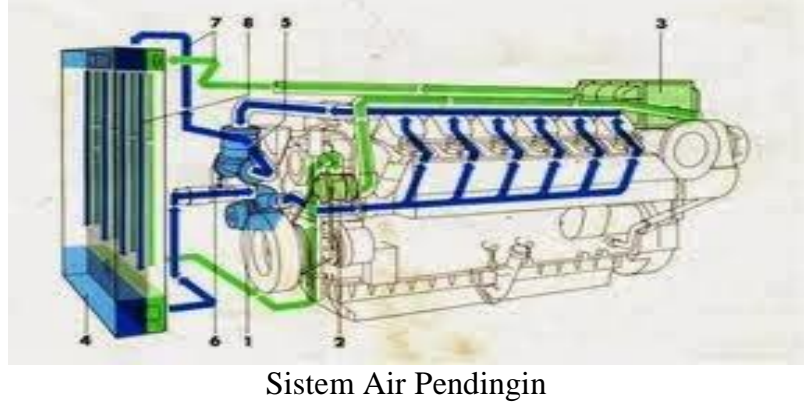

b) Level air di expansion tank

Expansion Tank harus diimbangi dengan topping up. Jika topping diperlukan, air segar bisa digunakan; namun jika diperlukan karena kebocoran, air yang diolah harus ditambahkan. Apabila terjadi penurunan terus menerus dari level air maka diindikasikan cacat.

c) Kondisi air pendingin

Kondisi air pendingin yang diolah harus diverifikasi secara teratur. Diskusikan hal ini dengan pemasok produk yang digunakan untuk perawatan, yang mungkin bisa mengatur tes yang Anda inginkan.

d) Fungsi kipas pada radiator.

$>$ Jika kipas digerakkan secara elektrik, fungsinya harus diverifikasi.

$>$ Jika digerakkan oleh belts dari mesin, belt-tension harus diperiksa secara teratur, agar tidak tergelincir.

$>$ Bisa juga dimanfaatkan dari waktu ke waktu untuk menghilangkan debu dan kotoran dari bagian udara radiator; misalnya dengan cara meniup.

B. Sistem LT-cooling

Sejauh ini sistemnya tertutup, poin yang sama seperti sistem HT cooling berlaku, kecuali:

a) Suhu Air Pendingin

Suhu ini tidak diatur secara termostatik, sehingga suhu air pendingin di inlet pendingin udara akan berfluktuasi, tergantung pada beban mesin dan suhu sekitar. Sampai dengan suhu 45 derajat celcius pada saluran pendingin udara, mesin bisa menghasilkan output nominalnya.Di atas suhu ini, pengurangan output harus diperhitungkan.

\section{Cylinder Head}

Cylinder Head merupakan besi cor lamellar yang pas dengan dua buah katup inlet (48) dan dua buah katup exhaust yang meluncur di dalam katup guide (4)

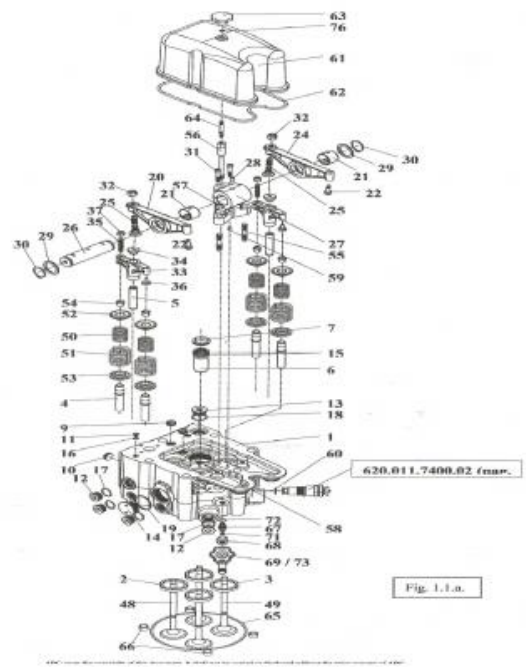

Komponen Cylinder Head 
Dalam pembongkaran Cylinder Head, maka tahapan yang harus dilakukan adalah sebagai berikut:

1. Drain semua part pada sistem air sehingga cylinder head bebas dari air

2. Lepaskan penutup cylinder head dengan melepas baut pada handle

3. Lepaskan cylinder head pipa ( pipa injeksi bahan bakar, pipa drain bahan bakar, dan pipa oli valve gear) dan lepaskan elbow outlet air.

4. Lepaskan semua bagian rocker lever (20-24) beserta braket (27) dan bridges (33), dan push rods. Lepaskan juga rumah nozzle dengan menggunakan alat nomro 620.083.1300.01, setelah melepas pipa injeksi coupling piece (82) dan cap nut segienam (83). Setelah melepas holder nozzle pasang kembali cap nut segienam.

5. Lepaskan cylinderhead dari gas outlet manifol dan udara masuk manifold.

6. Longgarkan mur dari cylinder head selama 2 kali ( pertama kali sekitar $90^{\circ}$ )

7. Tinggalkan cylinder head artinya dari semua mata baut.

8. Hal yang perlu di perhatikan : jangan rusak gasket pada permukaan cylinderhead pada bagiann casket. Hingga, letakan selalu cylinder head pada sebuah objek kayu.

Kebocoran Sistem Pendingin Cylinder Head dapat disebabkan oleh beberapa faktor diantaranya adalah sebagai berikut :

1. Seal yang melebihi lifetime

2. Pemasangan Seal yang tidak sesuai dengan manual book pemasangan

3. Cylinder Head Retak

4. Karet Seal Tidak Terpasang

Cara Mengetahui Adanya Kebocoran Sistem Pendingin Pada Cylinder Head adalah dengan

1. Melihat Temperatur Cylinder Head Turun Saat Sedang Operasi

2. Level Air Sistem Pendingin Turun

3. Level Oli Naik

4. Stick Penujuk Oli menunjukan bercak-bercak air

5. Terdapat Kerak Air Saat Cylinder Head Di Bongkar

6. Di Tes Dengan Menggunakan Alat Tes Kebocoran

Cara mengatasi troubelshoting kebocoran saluran pendingin adalah sebagai berikut :

Penyebab Kebocoran Cylinder Head

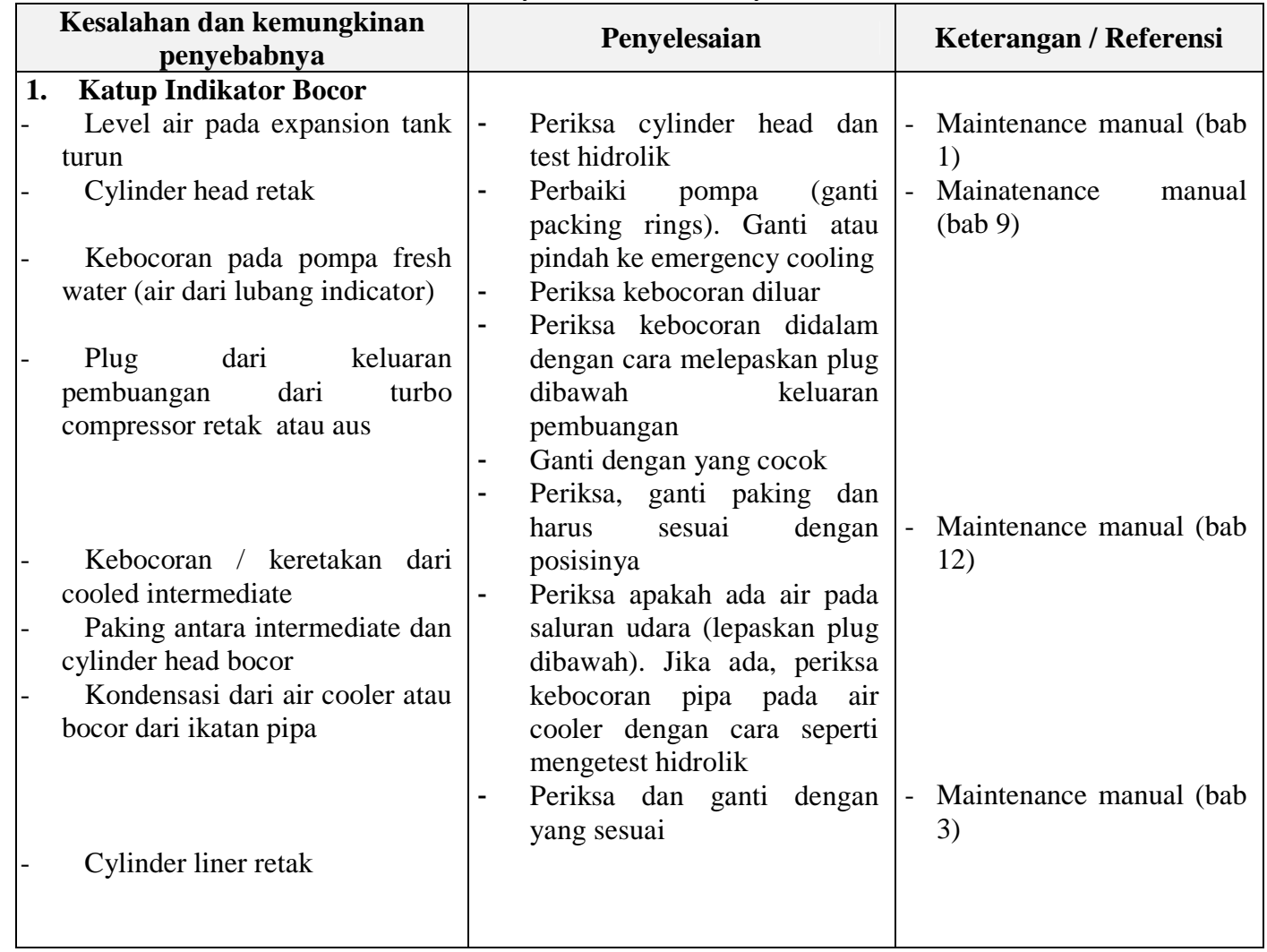




\begin{tabular}{|c|c|c|}
\hline $\begin{array}{c}\text { Kesalahan dan kemungkinan } \\
\text { penyebabnya }\end{array}$ & Penyelesaian & Keterangan / Referensi \\
\hline $\begin{array}{l}\text { 2. Kebocoran air pada bagian } \\
\text { luar } \\
\text { Air berasal dari bawah } \\
\text { cylinder head } \\
\text { - Air keluar dari lubang indicator } \\
\text { pada cylinder blok } \\
\text {-Kebocoran pada cover dari } \\
\text { cleaning openings } \\
\text { - Kebocoran paking pada pompa sea- } \\
\text { water } \\
\text { - Kebocoran pompa fresh water (air } \\
\text { bocor dari lubang indicator) }\end{array}$ & $\begin{array}{l}\text { - } \text { Kebocoran pada cylinder } \\
\text { liner } \quad \text { Ring paking besi tidak } \\
\text { kencang } \\
\text { - Collar dari cylinder liner } \\
\text { rusak } \\
\text { Karet dari seal O-ring pada } \\
\text { jalur lintasan air bocor } \\
\text { Kebocoran dari seal o-ring, } \\
\text { dan harus diganti } \\
\text { Lepaskan cylinder head dan } \\
\text { ganti yang bocor } \\
\text { Ganti pompa dan ganti } \\
\text { paking yang baru. Pindahkan } \\
\text { operasi ke emergency } \\
\text { cooling } \\
\text { Ganti pompa - ganti paking } \\
\text { yang baru. Pindahkan operasi } \\
\text { ke emergency cooling }\end{array}$ & $\begin{array}{l}\text { - Maintenance Manual (bab } \\
\text { 3) } \\
\text { - Maintenance Manual (bab } \\
\text { 9) } \\
\text { - Maintenance Manual (bab } \\
\text { 9) }\end{array}$ \\
\hline $\begin{array}{l}\text { 3. Air pada oli } \\
\text { - Kebocoran air pada cylinder } \\
\text { head } \\
\text { - Kebocoran pada oil coolers } \\
\text { - Kebocoran air pada liner }\end{array}$ & $\begin{array}{l}\text { - Periksa plug joints pada } \\
\text { cylinder head dimana perlu } \\
\text { mengganti joints dan } \\
\text { melakukan pengujian } \\
\text { hydraulic pada cylinder head } \\
\text { Periksa oil cooler dan } \\
\text { lakukan pengujian hidrolik } \\
\text { pada cylinder } \\
\text { Cari kebocoran air pada } \\
\text { lubang indicator, cari dan } \\
\text { ganti kebocoran dari O-rings, } \\
\text { periksa kandungan air pada } \\
\text { oli (max 0,5 \% m } / \mathrm{m} \text { ). Jika } \\
\text { perlu ganti oli. }\end{array}$ & $\begin{array}{l}\text { - Maintenance Manual (bab } \\
\text { 1) } \\
\text { - Maintenance Manual (bab } \\
\text { 12) } \\
\text { - Maintenance Manual (bab } \\
\text { 3) }\end{array}$ \\
\hline Catatan & $\begin{array}{l}\text { Cylinder dimana air ditemukan } \\
\text { tidak merupakan faktor utama } \\
\text { kegagalan. } \\
\text { Air dapat juga masuk menuju } \\
\text { cylinder melalui katup keluaran } \\
\text { pada keluaran manifold. } \\
\text { Untuk kejadian khusus, dimana } \\
\text { air dapat ditemukan kembali } \\
\text { pada oli, kandungan air harus } \\
\text { diperiksa (max } 0.5 \% \mathrm{~m} / \mathrm{m} \text { ) } \\
\text { Jika oli telah banyak } \\
\text { terkontaminasi dengan air, } \\
\text { element dari filter oli harus } \\
\text { diganti, crankcase dan oil tank } \\
\text { harus dibersihkan dan oil circuit } \\
\text { harus dibersihkan dengan }\end{array}$ & \\
\hline
\end{tabular}




\begin{tabular}{|l|l|l|}
\hline $\begin{array}{c}\text { Kesalahan dan kemungkinan } \\
\text { penyebabnya }\end{array}$ & \multicolumn{1}{|c|}{ Penyelesaian } & Keterangan / Referensi \\
\hline & $\begin{array}{l}\text { pembersih oli atau sejenisnya. } \\
\text { Satu atau dua jam setelah engine } \\
\text { berjalan, cover dari penutup } \\
\text { cylinder head harus dilepaskan } \\
\text { dan sample dari oli harus diambil } \\
\text { guna menentukan kandungan air } \\
\text { pada oli }\end{array}$ & \\
\hline
\end{tabular}

\section{Desain Produk}

Menurut Muhajirin, M.Pd (2011). Desain merupakan suatu proses yang dapat dikatakan telah seumur dengan keberadaan manusia di bumi. Hal ini sering tidak kita sadari. Akibatnya, sebagian dari kita berpendapat seolah-olah desain baru dikenal sejak zaman modern dan merupakan bagian dari kehidupan modern. Dalam bahasa sehari-hari kata desain sering diartikan sebagai sebuah perancangan, rencana atau gagasan. Dalam kamus besar Bahasa Indonesia dikatakan bahwa desain sepadan dengan kata perancangan.Desain produk adalah salah satu aktivitas yang merancang suatu bentuk kemudian diproses melalui proses produksi dan hasil akhirnya menjadi suatu barang atau produk yang dihasilkan dari proses produksi tersebut serta nilai dan kegunaanya dapat memenuhi keinginan konsumen yang disesuaikan dengan perkembangan zaman dan waktu yang berubah-ubah. Desain produk juga merupakan suatu profesi yang kegiatannya berkaitan dengan suatu proses inovasi teknologi.

Produk

Menurut Agus Ahyari produk merupakan sebagai hasil dan kegiatan produksi akan mempunyai wujud tertentu, mempunyai sifat fisik dan kimia tertentu. Disamping itu akan datang tenggang waktu antara saat diproduksi dengan saat dikonsumsi (Ahyari, 1985: 8). Karl T. Ulrich mendefinisikan produk sebagai sesuatu yang dijual oleh perusahaan kepada pembeli (Ufrich, 2001:2).

\section{Proses}

Proses adalah merupakan urutan langkah - langkah pengubahan sekumpulan output . Proses pengembangan produk adalah urutan langkah - langkah atau kegiatan - kegiatan dimana suatu perusahaan berusaha untuk, menyusun, merancang dan mengkomersilkan suatu produk. Proses Pengembangan produk yang umum terdiri dari enam tahap.Proses ini diawali dengan suatu fase perencanaan, yang berkaitan dengan kegiatan - kegiatan pengembangan teknologi dan penelitian tingkat lanjut.

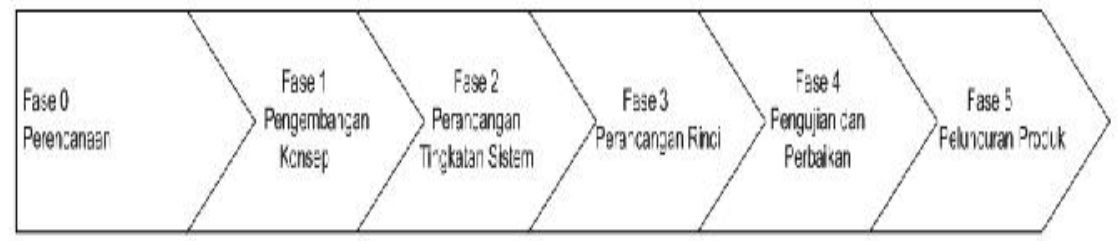

Proses Pengembangan Produk

\section{Proses Perancangan}

Perancangan system produksi diawali dengan merancang produk yang akan diproduksi. Hasil keputusan desain produk selanjutnya ditransmisikan ke operasi sebagai spesifikasi produksi, dan spesifikasi produksi merumuskan karakteristik produk dan memungkinkan pelaksanaan produksi. Desain merupakan hal yang sangat penting bagi kelangsungan hidup perusahaan. Berbagai desain produk baru diciptakan karena orang percaya bahwa ada kebutuhan akan produk tersebut. Kemajuan teknologi berdampak pada desain-desain produk yang secara terus menerus mengalami perkembangan pesat. Sebagian besar perusahaan secara kontinyu melakukan perubahan, perbaikan dan pengembangan terhadap produk- produk lama yang telah usang dan ketinggalan jaman. Dalam hal ini dibutuhkan perancangan produk yang mempunyai kepekaan dan ide-ide baru yang dapat terus dikembangkan.

\section{Proses Perancangan Produk}

Pokok - pokok dalam proses perancangan produk dapat dijelaskan sebagai berikut. Konsep perancangan merupakan tahap awal dari proses produksi yang berkaitan dengan pengembangan ide - ide, yang dapat dikembangkan dari pasar yang sudah ada atau dari teknologi yang sudah ada, hanya saja tidak 
semua ide tersebut dapat dikembangkan menjadi suatu produk baru. Ide - ide untuk mengembangkan suatu produk dapat dikembangkan bila memenuhi beberapa pengujian atau analisis, antara lain potensi pasar, kelayakan dari segi keuangan, dan kesesuaian operasi. Konsep perancangan disetujui maka selanjutnya dilakukan perancangan sebuah prototipe yang kemudian dilanjutkan dengan pembuatan prototipe dan proses pengembangannya. Prototipe merupakan bentuk tiruan yang menyerupai produk akhirnya. Prototipe yang dibuat kemudian dilakukan pengujian baik pengujian pasar maupun pengujian terhadap penampilan teknis produk. Jika pengujian telah memenuhi syarat selanjutnya dilakukan.

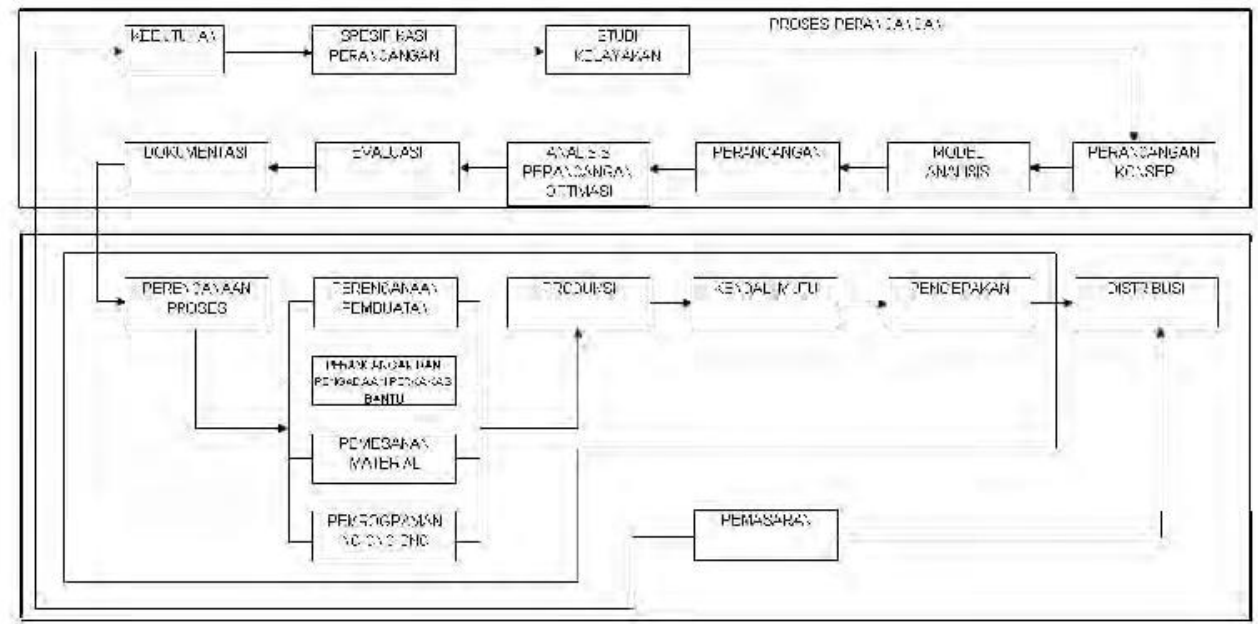

Diagram Alir Proses Perancangan dan Pembuatan

\section{METODE PENELITIAN}

Variabel dan Definisi Operasional

Yang termasuk dalam indikator variabel keputusan dalam penilitian adalah sebagai berikut :

a. Lifetim Material $\left(\mathrm{X}_{1}\right)$

b. Lama Ketepatan Pemasangan $\left(\mathrm{X}_{2}\right)$

Variabel keputusan merupakan suatu indikator untuk mencapai variabel tujuan. Yang mana variabel tujuan adalah untuk mengetahui tingkat kebocoran.

\section{Metode Analisa Data}

Data yang telah dikumpulkan selanjutnya diolah dan diintrepretasikan untuk menjawab tujuan penelitian. Pada tahap ini digunakan metode perancangan produk.

Berikut ini merupakan flowchart dari penelitian ini.

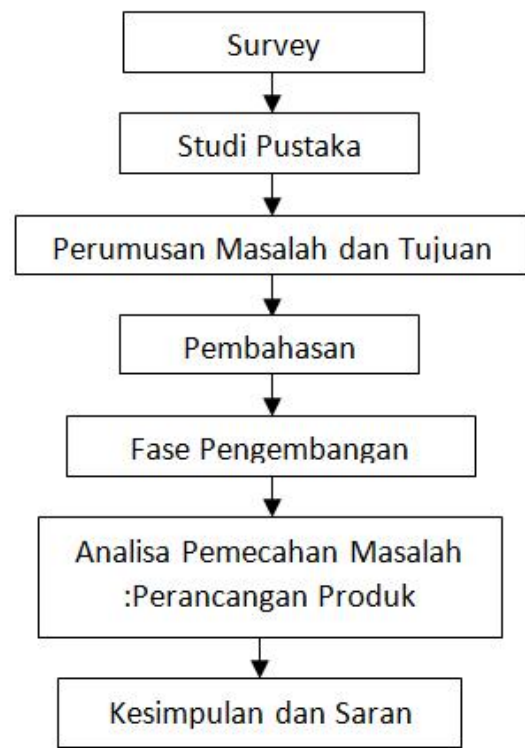

Flowchart Penelitian 


\section{HASIL DAN PEMBAHASAN \\ Deskripsi Produk}

Alat Tes Kebocoran Air Cylinder Head pada Mesin Anglo Belgian Corp. 12VDCZ adalah alat yang digunakan untuk mengetahui kebocoran Air pada Cylinder yang sedang di lepas dari Mesin. Sehingga dengan adanya alat ini dapat membantu kinerja PT PLN (Persero) dalam rangka mengurangi pekerjaan berulang dan menghemat biaya pemeliharaan .

\section{Perencanaan Produk}

Rencana proses dimulai dengan mengidentifikasi peluang - peluang pengembangan produk. Dalam hal ini sumber yang didapat adalah berdasar dari penelitian. Sehingga dari penelitian tersebut dapat diketahui kegagalan dan keluhan yang dialami oleh petugas. Dalam pemeliharaan kebocoran air pada cylinder head komponen Cylinder Head dilepas untuk di lakukan pengecekan namun tidak adanya alat untuk mengetes kebocoran sehingga pengecekan hanya dilakukan secara visual dan Cylinder Head yang bocor diganti dengan Cylinder Head yang baru untuk dipasang kembali agar mesin dapat beroperasi

\section{Pengembangan Konsep}

Setelah dilakukukan penelitian maka perlu dilakukan identifikasi kebutuhan pelanggan dengan membuat kuisioner. Responden berjumlah 8 petugas jumlah seluruhnya petugas pemeliharan pemeliharaan, 1 Supervisor Pemeliharaan dan 1 Manager di PLTD Poka . Pengetahuan responden pada aspek teknis yang menyangkut pemeliharaan Mesin Anglo Belgian Corp. 12 VDCZ telah mendapat pelatihan dan tugas rutin yang berkaitan dengan pemeliharaan Sistem Air Pendingin Cylinder Head sehingga pengetahuan yang didapat merata.

\section{Perancangan Tingkatan Sistem}

Dalam fase ini mencakup arsitektur produk/alat dan gambaran rakitan akhir untuk produk/alat ini. Untuk perancangan awal maka dibutuhkan bagian-bagian dari setiap komponen di dalam Alat Tes Kebocoran Air Cylinder Head pada Mesin Anglo Belgian Corp. 12VDCZ. Berikut hal-hal yang dibutuhkan dalam perancangan Alat Tes Kebocoran Air Cylinder Head pada Mesin Anglo Belgian Corp. 12VDCZ. Perancangan alat akan memberikan kinerja maksimal pada hasil ketika perancangan alat dijalankan sesuai prosedur. Memperhatikan karakteristik tiap-tiap bagian sangat penting, terkait dengan fungsi dan kinerja alat untuk dapat bekerja secara maksimal. Dalam tahapan perancangan diperlukan suatu gambaran secara menyeluruh dari sistem yang akan dibuat. Dengan adanya gambaran tersebut, diharapkan dapat memberikan wawasan berkaitan dengan alat yang dibuat. Dalam hasil diskusi dan konsultasi dengan pegawai PLTD Poka bagian Pemeliharaan maka dapat dijelaskan Desain Akhir Alat Tes Kebocoran pada Cylinder Head yaitu:

\section{A. Desain Dudukan Cylinder Head}

Dudukan Cylinder Head ini dilengkapi dengan:

1. 4 (empat) buah dudukan seal air bawah yang berfungsi sebagai tempat seal Cylinder Head agar air tidak keluar dari Cylinder Head.

2. 6 (enam) buah baut utama untuk mengikat Cylinder Head yang berfungsi agar Cylinder Head dapat terikat kuat dan seal dudukan dapat terpasang dengan kuat serta tidak terdapat air yang keluar melewati saluran seal bagian bawah.

3. Plat besi yang berfungsi sebagai tempat menempelnya baut dan tempat dudukan seal untuk menahan air agar tidak keluar dan tertahan di dalam sistem saluran air pendingin.

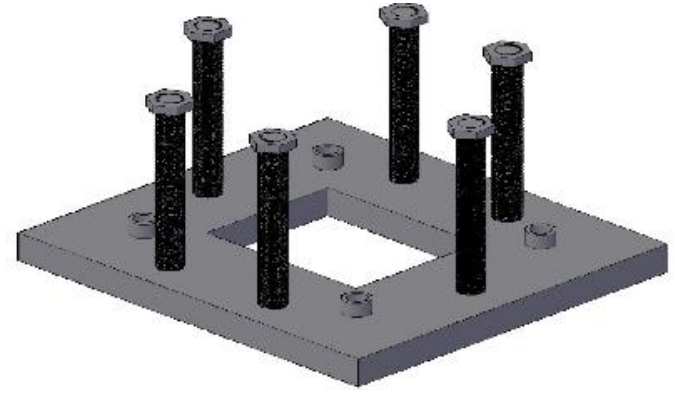

Desain Dudukan Cylinder Head

\section{B. Desain Penutup Saluran Air Atas}

Penjelasan desain Penutup Saluran Atas adalah sebagai berikut :

1. 3 (tiga) lubang sebagai tempat dudukan penutup agar penutup dapat terikat dengan Cylinder Head dengan kuat. 
2. Tempat dudukan Seal sebagai tempat Seal agar air tidak keluar melalui celah antara penutup dan Cylinder Head.

3. Ulir pada desain berukuran baut 17 yang berfungsi sebagai tempat connecting (penghubung) antara penutup dengan selang Pressure Pump.

4. Terdapat lubang yang berdekatan dengan ulir atas sebagai tempat masuknya air dari selang yang di pompa oleh Pressure Pump.
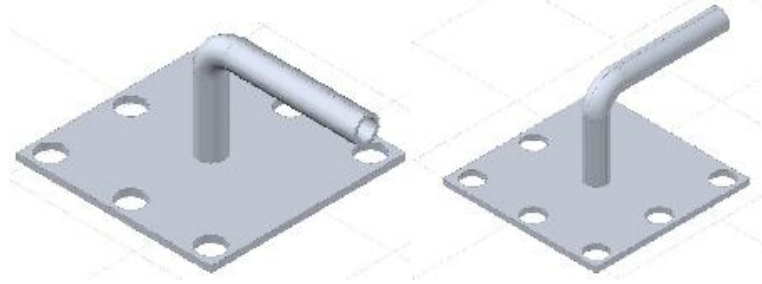

\section{Pressure Pump}

Desain Penutup Saluran Air Atas

Pressure Pump yang dibutuhkan sesuai dengan desain adalah Pressure Pump yang memiliki tekanan lebih dari $15 \mathrm{Kg} / \mathrm{ms}$ dan memiliki selang dengan baut ulir dalam dengan ukuran baut 17 .

\section{Inventarisasi Komponen}

Komponen yang dibutuhkan dalam pembuatan Alat Tes Kebocoran pada Cylinder Head sesuai dengan Desain Akhir adalah sebagai berikut
1. Alat Pressure Test dengan kekuatan lebih dari $15 \mathrm{~kg} / \mathrm{ms}$
2. Besi plat dengan ukuran tebal $3 \mathrm{~mm}$
3. Baut dengan ukuran 27
4. Mur dengna ukuran 27
5. Besi dengan ukuran diamter $7 \mathrm{~cm}$ dan tinggi $10 \mathrm{~cm}$
1 Buah
1 Lembar
6 Buah
6 Buah
1 Buah

\section{Pembuatan Urutan Pekerjaan}

Tahapan Pekerjaan Pembuatan Alat Tes Kebocoran pada Cylinder Head adalah sebagai berikut:

1. Pembuatan Dudukan Cylinder Head

Berikut adalah tahapan dalam pembuatan dudukan Cylinde Head:

- Memotong plat sesuai luasan yang ada;

- Menyambungkan bagian A dengan bagian B dengan cara mengelas pada kedua bagian tersebut;

- $\quad$ Setelah bagian A dan bagian B tersambung, kemudian mengelas bagian tersebut dengan baut 27 sesuai dengan titik yang telah di tentukan;

- Memotong besi berlubang sebanyak 4 (empat) buah sesuai dengan ukuran yang telah ditentukan;

- Mengelas potongan besi tersebut sesuai dengan titik yang telah di tentukan.

2. Pembuatan Penutup Inlet Air Sistem pendingin

- $\quad$ Memotong plat sesuai ukuran yang telah di tentukan;

- Melubangi plat sesuai dengan ukuran yang telah di tentukan; dan

- $\quad$ Menggabungkan plat yang telah dilubangi dengan baut 17.

3. Mencari alat Pressure Test dengan tekanan lebih dari $15 \mathrm{~kg} / \mathrm{ms}$.

\section{Pembuatan Alat}

Tahapan pembuatan Alat Tes Kebocoran pada Cylinder Head adalah sebagai berikut:

1. Membuat dudukan Cylinder Head;

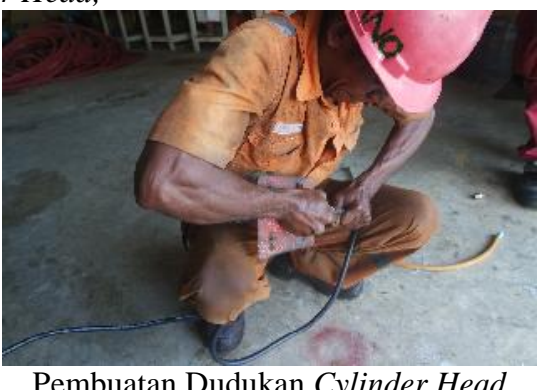

Pembuatan Dudukan Cylinder Head 
2. Membuat penutup inlet air sistem pendingin;

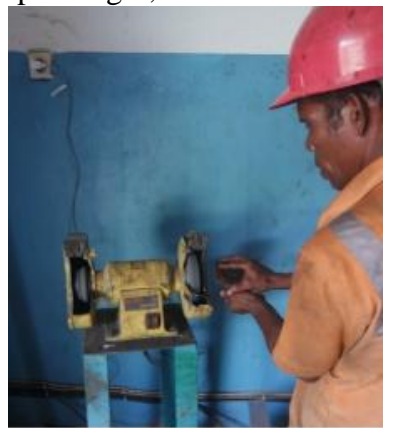

Pembuatan Penutup Inlet Air Sistem pendingin

3. Alat Pressure Test dengan Tekanan Lebih dari 5 Bar

Alat Pressure Test yang digunakan dalam Alat Tes Kebocoran pada Cylinder Head adalah alat Pressure Test dengan merk NANKAI dengan spesifikasi sebagai berikut :

Spesifikasi Alat Pressure Test dengan Merk NANKAI

\begin{tabular}{|l|c|}
\hline \multicolumn{1}{|c|}{ Nama } & Hydraulic Pressure Test Pump \\
\hline Merk & NANKAI \\
\hline Type & SY-60 \\
\hline Tekanan Maksimum & $6 \mathrm{MPA}$ \\
\hline Stroke & $35 \mathrm{~mm}$ \\
\hline Rata-rata Air sekali Stroke & $13 \mathrm{c.c}$ \\
\hline Kapasitas Tangki Air & $5 \mathrm{Liter}$ \\
\hline Berat & $5 \mathrm{Kg}$ \\
\hline Dimensi & $310 \times 310 \times 190(\mathrm{~mm})$ \\
\hline Aksesoris & $\begin{array}{c}\text { Pressure hose } 1 \\
\text { Bushing } 1 / 2 \times 1 / 4\end{array}$ \\
\hline Bahan & Steel Tank \\
\hline
\end{tabular}

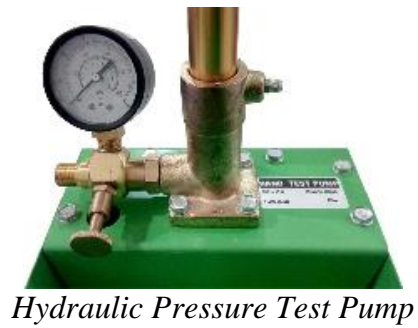

Prosedur penggunaan Alat Pressure Test sesuai dengan penjelasan yang diuraikan oleh PT. NANKAI adalah sebagai berikut:

1. Memasang katup penghenti pada pipa uji;

2. Mengisi pipa uji dengan air dari service water atau sumber pasokan lainnya;

3. Ketika pipa uji sudah terisi dengan air, langkah selanjutnya adalah mengeluarkan udara pada pipa dan menutup katup kran;

4. Menghubungkan tester dan pipa uji dengan 1 (satu) set selang penahan tekanan yang sudah terpasang;

5. Mengisi tangki air tester dengan air dan mengoperasikan pompa;

6. Membuka katup penghenti pipa uji dan melanjutkan tahap pengoperasian untuk diisi dengan air;

7. Ketika alat pengukur tekanan (No. 23) yang dipasang ke tester naik ke level tekanan yang dibutuhkan, maka pengoperasian pompa diberhentikan;

8. Jika tekanan tidak turun, maka pengujian pipa yang dilakukan sudah sempurna;

9. Namun, jika tekanan menurun maka hal ini menunjukkan bahwa terdapat kebocoran yang terjadi pada pipa uji.

\section{SOP Penggunaan Alat}

Adapun penggunaan Alat Tes Kebocoran pada Cylinder Head ini adalah sebagai berikut:

1. Berdoa sebelum memulai pekerjaan;

2. Dalam mengoperasikan Alat Tes Kebocoran pada Cylinder Head minimal dilakukan oleh 2 (dua) orang; 
3. Menggunakan sarung tangan dan Alat Pelindung Diri (APD) sesuai dengan standar yang sudah ditentukan;

4. Menyiapkan alat pendukung lainnya;

5. Memastikan Cylinder Head yang diuji bersih dari kotoran;

6. Memasang Karet no 66 pada 4 (empat) lubang yang terdapat di dudukan tersebut;

7. Memasang Cylinder Head pada Alat dudukan tersebut.

8. Setelah Cylinder Head sudah terpasang pada alat dudukan, langkat selanjutnya adalah mengikat baut hingga kencang.

9. Masukan air ke dalam saluran air pendingin yang terdapat pada Cylinder Head hingga penuh.

10. Memperhatikan semua bagian Cylinder Head apakah terdapat kebocoran atau tidak. Apabila terdapat kebocoran pada karet No 66, maka perlu mengencangkan baut Cylinder Head sehingga tidak ada kebocoran.

11. Apabila Air sudah penuh, langkah selanjutnya adalah memasang alat penutup Cylinder Head yang sudah tersambung dengan alat Pressure Test.

12. Mengikat penutup dengan baut hingga kuat.

13. Mengisi air pada alat Pressure Test, kemudian memompa Alat Pressure Test hingga tekanan air sampai pada tekanan 3 Bar.

14. Menutup kran pengunci pada alat Pressure Test.

15. Melihat ada atau tidaknya kebocoran pada Cylinder Head.

16. Jika tidak terdapat kebocoran, maka tandai Cylinder Head bahwa tidak ada kebocoran (siap di gunakan) dan apabila terdapat kebocoran pada Cylinder Head maka pastikan letak kebocoran secara visual.

17. Apabila terdapat kebocoran pada bagian-bagian yang masih dapat diperbaiki atau diganti maka ganti bagian tersebut, kemudian melakukan tes kembali dengan alat ini.

18. Apabila kebocoran disebabkan karena adanya keretakan pada Cylinder Head maka tandai dengan tipe X pada bagian yang retak, kemudian tandai Cylinder Head bahwa tidak bisa digunakan (rusak).

19. Setelah Pengetesan dilakukan, buka kran air agar tekanan air turun mencapai tekanan normal.

20. Membuka baut penutup Cylinder Head dan melepaskan penutup pada Cylinder Head.

21. Membuang air yang terdapat dalam Cylinder Head.

22. Membuka dudukan pada Cylinder Head.

23. Melepaskan dudukan Cylinder Head dari Cylinder Head.

24. Melepaskan Karet Seal dari dudukan dan meletakkan pada tempatnya.

25. Membersihkan Alat Tes Kebocoran pada Cylinder Head.

26. Menyimpan Alat Tes Kebocoran pada tempat penyimpanan.

\section{Uji Coba Alat}

Uji Coba Dilaksanakan Di PLTD POKA pada Tanggal 14 April 2017 dengan jumlah Cylinder Head yang diuji sebanyak 8 buah dengan hasil uji sebagai berikut:

Hasil Pengujian Cylinder Head

\begin{tabular}{|c|l|c|c|c|}
\hline NO & Cylinder Head No & Tekanan & Hasil Uji & Keterangan \\
\hline 1 & Cylinder No 1 & 3 Bar & BAIK & \\
\hline 2 & Cylinder No 2 & 3 Bar & BAIK & \\
\hline 3 & Cylinder No 3 & 3 Bar turun Hingga 2 Bar & RETAK & Retak pada bagian dalam \\
\hline 4 & Cylinder No 4 & 3 Bar turun Hingga 2 Bar & RETAK & Retak pada bagian dalam \\
\hline 5 & Cylinder No 5 & 3 Bar & BAIK & \\
\hline 6 & Cylinder No 6 & 3 Bar & BAIK & \\
\hline 7 & Cylinder No 7 & 3 Bar & BAIK & \\
\hline 8 & Cylinder No 8 & 3 Bar & BAIK & \\
\hline
\end{tabular}

\section{Analisa Kegagalan dan Tindakan Perbaikan}

Dari hasil uji coba pertama di dapatkan kebocoran pada saat bagian penutup Cylinder Head. Selanjutnya untuk memperbaiki kegagalan pertama tersebut perlu dilakukan penambahan seal no dan kemudian diikatkan kembali. Hal ini dilakukan agar tidak terdapat kebocoran kembali. Pada uji coba yang kedua sudah tidak ditemukan kembali kebocoran pada bagian tersebut. 


\section{Analisis Kerja Alat}

Dari hasil uji coba alat terbukti bahwa Alat bekerja sesuai dengan fungsi yang diinginkan dan mempermudah dalam bekerja. Hal ini dibuktikan dari hasil data primer yang diperoleh melalui data kuesioner dan hasil wawancara. Pihak Responden pengumpulan data primer melalui teknik kuesioner adalah pegawai Pemeliharaan di Unit PLTD Poka. Sedangkan pihak Responden pengumpulan data primer melalui teknik wawancara adalah Bapak Manajer Unit PLTD Poka.

Jumlah dari responden kuesioner adalah 10 orang sedangkan responden wawancara adalah 1 orang. Masa kerja responden di PLTD Poka yang merupakan pegawai Pemelirahaan sebagian besar memiliki masa kerja antara 5 sampai dengan 10 tahun. Berikut adalah diagram masa kerja responden di PLTD Poka:

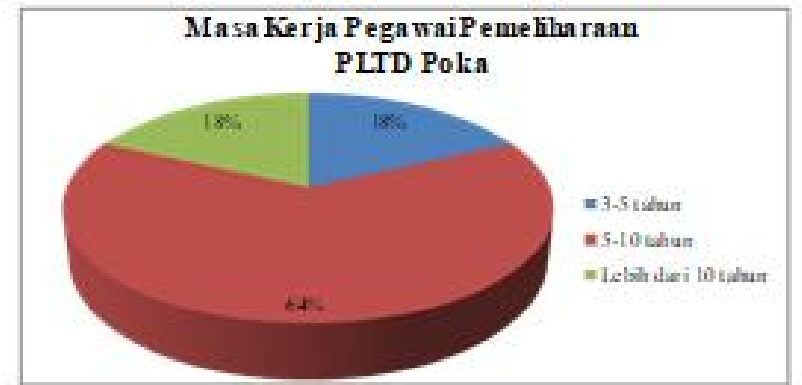

Diagram Masa Kerja Pegawai Pemeliharaan di Unit PLTD Poka

\section{A. Analisis Kinerja Alat Pendeteksi Kebocoran pada Cylinder Head}

a. Analisis Operasi

Dengan Adanya Alat Pendeteksi Kebocoran ini pemeliharaan berulang karena kesalahan pemasangan Cylinder Head dapat dihilangkan sehingga kesiapan mesin untuk melistriki kota ambon dapat lebih cepat standby untuk operasi. Berdasarkan hasil analisa pelaksanaan pekerjaan pengantian Cylinder Head adalah 5 (lima) jam jadi apabila pemeliharaan di lakukan berulang maka kehilangan 4 (empat) jam standby operasi mesin. Mesin Anglo Belgian Corp 12 VDCZ PLTD poka memiliki daya mampu mesin sebesar $1800 \mathrm{KW}$ yang apabila kehilangan waktu 4 (empat) jam karena pemeliharaan berulang maka PLTD poka kehilangan $7200 \mathrm{KWh}$ siap jual yang apabila di rupiahkan dengan asumsi harga $1 \mathrm{KWh} 1372$ rupiah maka senilai Rp. 9.878.400,- dengan pembuatan sehingga dengan biaya pembuatan alat sebesar Rp. 1.762.000,-. Dengan adanya alat ini, dapat menghemat biaya akibat tidak masuknya mesin pada sistem sebesar Rp. 8.116.400,-.

b. Analisis Biaya Pemeliharaan

Dengan adanya alat ini kebocoran Cylinder Head yang dapat yang dapat memicu tercampurnya air kedalam oli dapat di cegah karena kondisi oli terkontaminasi memiliki syarat apabila melebihi batas maksimalnya maka oli harus diganti semuanya namun dengan menggunakan alat ini dapat mencegah hal tersebut sehingga dapat menghemat penggantian oli pada mesin Anglo Belgian Corp Poka. Penggantian semua Oli Mesin Anglo Belgian Corp PLTD membutuhkan 6 drum oli dengan harga sebesar Rp. 5.000.000,- per drum sehingga di kalikan 6 drum total sebesar Rp.30.000.000 . dengan pembuatan alat ini sebesar Rp. 1.762.000 Ini dapat menghemat penggunaan oli sebesar Rp. 28.238.000,-

c. Analisis Kinerja Alat

Berdasarkan hasil kuesioner dengan menggunakan metode kuantitatif terhadap 11 responden di PLTD Poka di dapatkan data hasil bahwa dengan adanya Alat Pendeteksi Kebocoran Air pada Cylinder Head Mesin Anglo Belgian Corp 12VDCZ PLTD Poka maka deteksi kebocoran lebih awal di deteksi kebocoran sebelum di pasang pada mesin sehingga pekerjaan berulang dapat di hindarkan dan pekerjaan menjadi lebih efektif. Selain itu pembuatan alat ini sangat mudah karena bahan2 sangat dengan mudah dapat ditemukan dan dengan Standing Operating Prosedur yang mudah di pahami sehingga pengguna dengan mudah menggunakan alat ini serta alat ini sangat dengan dimensi yang kecil dan ringan sehingga mudah di bawa dan disimpan.

\section{KESIMPULAN}

Dari Pembuatan Alat Dan Analisis Kinerja yang penulis uraikan pada bab IV secara garis besar diambil kesimpulan sebagai berikut :

1. Pada Mesin Anglo Belgian Corp. 12VDCZ PLTD Poka belum ada alat untuk mengetahui kebocoran pada cylinder head sehingga pemeriksaan hanya dengan visual saja. 
2. Alat Pendeteksi Kebocoran pada telah di uji terhadap 8 cylinder head yang standby dengan tekanan air yang sama dengan keadaan operasi di dapatkan cylinder tidak terdapat kebocoran sebanyak 6 buah untuk standby dan 2 buah cylinder terdapat kebocoran pada bagian dalam karena adanya retakan sehingga tidak dapat di perbaiki.

3. Dengan Adanya Alat Pendeteksi Kebocoran ini pemeliharaan berulang karena kesalahan pemasangan Cylinder head dapat dihilangkan sehingga kesiapan mesin untuk melistriki kota ambon dapat lebih cepat standby untuk operasi. Dengan adanya alat ini, dapat menghemat biaya akibat tidak masuknya mesin pada sistem sebesar Rp. 8.116.400,--

4. Dengan adanya alat ini kebocoran cylinder head yang dapat yang dapat memicu tercampurnya air kedalam oli dapat di cegah karena kondisi oli terkontaminasi memiliki syarat apabila melebihi batas maksimalnya maka oli harus diganti semuanya namun dengan menggunakan alat ini dapat mencegah hal tersebut sehingga dapat menghemat penggantian oli pada mesin Anglo Belgian Corp Poka. dengan pembuatan alat ini sebesar Rp. 1.762.000 Ini dapat menghemat penggunaan oli sebesar Rp. 28.238.000

5. Dengan hasil kuisioner pada 11 responden pada PLTD Poka di dapatkan hasil bahwa dengan adanya Alat Pendeteksi Kebocoran Air pada Cylinder Head Mesin Anglo Belgian Corp 12VDCZ PLTD Poka maka deteksi kebocoran lebih awal di deteksi kebocoran sebelum di pasang pada mesin sehingga pekerjaan berulang dapat di hindarkan dan pekerjaan menjadi lebih efektif. Selain itu pembuatan alat ini sangat mudah karena bahan2 sangat dengan mudah dapat ditemukan dan dengan Standing Operating Prosedur yang mudah di pahami sehingga pengguna dengan mudah menggunakan alat ini serta alat ini sangat dengan dimensi yang kecil dan ringan sehingga mudah di bawa dan disimpan.

\section{DAFTAR PUSTAKA}

. Anglo Belgian Corps. General Information VDZC-Engine. Belgia -Anglo Belgian Corps. Anglo Belgian Corps. Operating Manual Diesel Engine ABC Type (M) DZC. Belgia -Anglo Belgian Corps.

Assauri, Sofjan. (2004)., Manajemen Produksi dan Operasi. Edisi Revisi. Jakarta: Lembaga Penerbit Fakultas Ekonomi Universitas Indonesia.

Corder, Anthony. (1992)., Teknik Manajemen Pemeliharaan terjemahan K. Hadi. Jakarta: Erlangga. . Pusdiklat. 2011. Diktat Pemeliharaan PLTD. PT PLN (Persero). Jakarta

Setiawan, F.D. (2008)., Perawatan Mekanikal Mesin Produksi. Yogyakarta: Maximus. . Udiklat Bogor. 2016. Diklat Berbasis Kompentensi (DBK) Pemeliharaan Sistem-Sistem PLTD. PT PLN ( Persero). Bogor

Ulrich Karl T, Eppinger, Steven D. (2001)., Perancangan Pengembangan Produk. Jakarta : Salemba Teknika. 
